\title{
Digital lecture recording: A cautionary tale.
}

\author{
Amy Johnston ${ }^{2 *}$ \\ Helen Massa ${ }^{1}$ \\ Tom Burne ${ }^{3}$

\section{For Nurse Education in Practice} \\ 1. Gold Coast campus, Griffith University, QLD AUSTRALIA \\ 2. Clinical Neuroscience, Eskitis Institute of Cell and Molecular Therapies, Griffith \\ University, Nathan Brisbane QLD 4111 AUSTRALIA \\ 3. Queensland Brain Institute, University of Queensland Brisbane 4072 AUSTRALIA \\ *Corresponding author: \\ Dr. A. N. B. Johnston, N48_1.19, SoNM, Griffith University, Brisbane, QLD 4111, \\ Australia Ph: +61 (0)7 37355223 \\ Fax: +61 (0)7 37355431 \\ Email: a.johnston@griffith.edu.au
}

Word count:

Disclosure: The authors have reported no conflicts of interest. The authors are not commercially funded. 


\begin{abstract}
:
Increasing application of information technology including web-based lectures and livelecture recording appears to have many advantages for undergraduate nursing education. These include greater flexibility, opportunity for students to review content on demand and the improved academic management of increasing class sizes without significant increase in physical infrastructure.

This study performed a quasi-experimental comparison between two groups of nursing students undertaking their first anatomy and physiology course, where one group was also provided access to streaming of recorded copies of the live lectures and the other did not. For the course in which recorded lectures were available student feedback indicated overwhelming support for such provision with $96 \%$ of students having accessed recorded lectures. There was only a weak relationship between access of recorded lectures and overall performance in the course. Interestingly, the nursing students who had access to the recorded lectures demonstrated significantly poorer overall academic performance $(\mathrm{P}<0.001)$. Although this study did not specifically control for student demographics or other academic input, the data suggests that provision of recorded lectures requires improved and applied time management practices by students and caution on the part of the academic staff involved.
\end{abstract}




\section{Introduction:}

Introductory anatomy and physiology classes for nursing students are frequently presented using didactic content-dense presentations that rely heavily on student engagement, lecturer performance and content management to maintain student attention (Davies et al., 2000; Weatherall, 2006). These courses are often considered difficult, and have relatively high failure rates (Courtenay, 1991; Johnston, 2009; Spitzer and Perrenoud, 2006). There is increasing interest in alternative and supplementary methods of supporting nursing students undertaking study in these content areas (Davies, et al., 2000; Gresty and Cotton, 2003; Johnston and McAllister, 2008). Alternative methods or increased student learning support increasingly includes utilization of on-line or web-based resources to supplement course delivery (Billings et al., 2005; Buckley, 2003; Jang et al., 2005; Salyers, 2005).

Web-based learning technologies, including digital recording of live lectures, are becoming increasingly common facilities offered by universities all over the world (Holliman and Scanlon, 2004; Scanlon et al., 2004). Perceived advantages of on-line lecture provision include improved flexibility and opportunity for mature-aged students (Kevern and Webb, 2004; Kornguth et al., 1994; Tanner, 2001). Thus these are ideal for nursing student cohorts who tend have a greater percentage of non-school leavers and who study while also undertaking a significant number of paid working hours (McCarey et al., 2006). These students also tend to have more carer responsibilities than other student populations (Kevern and Webb, 2004; McCarey, et al., 2006) and thus often request more flexible study patterns. Current literature often focuses on the advantages of such technologies to students and on the role of the academic in facilitating engaging and effective learning experiences via a recorded medium (McNeill et al., 2007; Phillips et al., 2007). With the increasing use of this technology, including digitally recorded lectures (audio or podcast and audiovisual), web- 
enhanced courses and various on-line learning tools, it was timely to undertake an assessment of the academic validity of such learning and teaching changes, in terms of nursing student academic performance. This technological support may offer flexibility, equity of access and ease of engagement. Whether this mode of learning support actually provides academically inexperienced students with a meaningful and effective learning experience that translates into equivalent or better outcome on standardized assessment tools such as exams and assignments, however, is largely unknown. Exploration of the effect of digital lecture supplementation to a first semester-long program of anatomy and physiology on academic outcome for students in their first year of study formed the primary focus of this study.

Web-based learning technologies cover many areas of academic learning and teaching, from content presentation, replacement of live (laboratory) classes with pre-recorded material to presentation of assessment tasks. Previous explorations of first-year Bachelor of Nursing (BN) students' perceptions of web-based intervention have focused heavily on usage and student satisfaction with such supports. Studies have indicated that students feel online activities enhance their learning, give them tools to practice learning and allow them to study at their own pace (Koch et al., 2010). However, students still appear to largely prefer face-toface lectures, but consider it optimal if online lectures supplement, rather than replace, the traditional mode of contact teaching (Cooke et al., 2012; Kiteley and Ormrod, 2009; Salamonson and Lantz, 2005).

The ability of didactic 'traditional' face-to-face lectures, undertaken by the majority of academics in tertiary settings, to enable deep and applied learning by students is often questioned (Jones, 2010; Scanlon, et al., 2004). Constructivist theories of education maintain that in order for deep learning to take place the student must be actively engaged, even 
constructing their own learning processes and that learning can occur in many different ways (Ramsden, 2007), which are often not catered for in traditional lectures (Jones, 2010). However, lectures remain the mainstay of many academics and, when delivered in an engaging and interactive style, can inspire and communicate content effectively to students (Hodson, 1998; McNeill, et al., 2007). With the majority of academic lecturers continuing to use lectures as their main teaching tool (Jones, 2010; Scanlon, et al., 2004) it would seem that consideration is best given to how this teaching format can best be adapted to ongoing student IT expectations and academic need. Moreover, the advent of lecture recording has encouraged debate on the relevance of live lectures in tertiary settings and the requirement for students to attend lectures in person.

One of the more common themes emerging from investigations of staff concerns about lecture recording relates to lecture attendance (Billings-Gagliardi and Mazor, 2007; Cardall et al., 2008; Jones, 2010). While some studies reported a drop-off in attendance in courses where lectures are recorded, others indicate that, due to work/life factors, students would not be able to attend anyway and thus low lecture attendance is in the nature of modern higher education whether or not alternative presentation is offered (Billings-Gagliardi and Mazor, 2007; Phillips, et al., 2007; Scanlon, et al., 2004; Wharrad, et al., 2005). It is certainly clear that, increasingly, Australian students, particularly nursing students (Salamonson and Andrew, 2006), are mirroring their international colleagues in that they undertake more paid employment during university terms and find that work impacts more on their study (Australian Vice-Chancellors' Committee, 2007; Rochford et al., 2009).

Web-based lectures or lecture recordings offer academic members of staff, laboratory support staff and students a flexible means of engaging with study at the tertiary level. Particularly in 
the 'science' areas of nursing curricula, often an area of concern and trepidation for students (Clancy et al., 2000; Johnston and McAllister, 2008), lecture recordings can serve as an ongoing revision tool for concerned students, as well allowing students to work at their own pace. Literature suggests overwhelmingly that digital recording of lectures is one way to enable students to interact with lecture material in a flexible manner (Cooke, et al., 2012; Kiteley and Ormrod, 2009; McNulty et al., 2009; Scanlon, et al., 2004). Such technologies have been incorporated into nursing education with success (Billings, et al., 2005; Buckley, 2003; Jang, et al., 2005; Kevern and Webb, 2004; Wharrad et al., 2005).

Student perception of online lecture presentation is overwhelmingly positive (Massingham and Herrington, 2009; McNeill, et al., 2007; Phillips, et al., 2007; Soong et al., 2006). While academics are voicing concerns about the impact of the supplementation (Phillips, et al., 2007) or replacement (Gosper et al., 2006; McNeill, et al., 2007) of live lectures with recorded lectures, studies conducted thus far appear to negate their concerns, at least in terms of student performance (Kiteley and Ormrod, 2009). Students report on par or better understanding and achievement in courses with on-line support (Gosper, et al., 2006; Massingham and Herrington, 2009). Moreover, where trials supplementing or replacing traditional lectures in biological sciences have been conducted in a systematic manner, student academic performance appears to have been on par with or better than those offered more traditional tertiary experiences (Goldberg and Dintzis, 2007; Goldberg and McKhann, 2000; McNulty et al., 2000; McNulty, et al., 2009; Solomon et al., 2004). Curiously though, studies focused on nursing students' perceptions of web-based lectures reveal more ambivalence than those in other disciplines (Koch, et al., 2010). This has often been related to technological difficulties or lack of IT facilities and 'academic' confidence in this student population (Green, et al., 2003; Green, et al., 2006; Kevern and Webb, 2004; Noble et al., 
2008; Rouse, 2000; Spitzer and Perrenoud, 2006). Reviews of computer-based learning in nursing education often point to confused or contradictory outcomes and the need for more systematic investigation (Lewis and Sewell, 2007).

Thus, the current study aimed to explore the impact of recording anatomy and physiology lectures in a nursing program for students on one but not the other campus of the same university on student performance. It examined student use and perception of access to digitally recorded live lectures. It also explored potential impacts of such access or no access to such technological provision on academic outcomes for students.

\section{Methods:}

Setting and sample

This study arose from a serendipitous event occurring in a unique university presentation of a core course in the bachelor of nursing degree. The same anatomy and physiology course for first year nursing students was offered on two geographically distinct campuses (Campus A \& B; separated by around 50km) of the same University by two different academic members of staff. One offering was lecture captured and the other was not; forming the basis of the study. The two staff members have worked closely together for some years to ensure as close as possible alignment of course delivery and curricular content. The courses are identical in terms of outline, text and text-online support, assessment regimen, course components (3 hours of lectures per semester week and $3 \mathrm{hr}$ laboratory classes each fortnight, laboratory class size 20-35 students maximum student: staff ratio 1:18) and assessment formulation or weighting. Assessment is both formative (lab manuals and content-based laboratory quizzes) and summative (mid and end of semester examinations). Both student cohorts had access to lecturer support time. Finally, differences between the two campuses were unlikely to be 
related to lecture/lecturer quality or ability to engage. Lecturers frequently shared lecture and other class presentations and both staff members have frequently been nominated for teaching excellence awards by students and staff. Both have recently been awarded University citations for learning and teaching excellence in this, their field of teaching expertise.

While two distinct and random student groupings were assessed on each campus there were many similarities. Previous offerings of this course on each campus have shown very similar distributions of overall results. Enrolments were 288 for Campus A and 211 for Campus B. Entry requirements were the same (it is the same degree program) and were the same as the previous year. While total numbers enrolled into this program at each campus increased, the proportion of increase was similar and there were no major changes to the student body included in this program. Lecture capture files were available for students on campus B to stream (audio and screen presentation) from their university course website and were made available within a few hours of the lecture. Due to concerns regarding intellectual ownership and copyright, students were not able to download the lectures. However, it should be noted that informal discussion with students indicated that some had actually manually copied the audio track from some of the lectures. Lectures were accessible for the remainder of the semester once uploaded onto teaching websites.

Data collection:

Data was collected retrospectively, not during the semester, as a normal part of ongoing reporting of student performance and course evaluation. Academic performance results were collated from university marks entry spread sheets (MESS) and lecture capture data was collected using the on-line simultaneous data collection software at the end of the semester. Students at campus B completed a survey in week 8 of semester, asking specifically about 
their experience of on-line lecture compared to on-line and face-to-face lecture options across all of their University courses. This survey was timed so that students had settled into the semester and had already performed some quiz assessments but had not completed their major examination-based assessments. Where qualitative data related specifically to their anatomy and physiology course it was collated for this study. Assessment items used were concordant at each campus, reviewed by both staff members to ensure equity across campuses and, wherever possible, assessment items were shared between campuses. Assessment was made up of 3 elements, mid and end of semester exams (both multiple choice and short answer questions) and laboratory-based assessment that was focused around activities conducted in the laboratory classes. The laboratory assessments were focused on laboratory content which, while not totally independent of the lecture content, did provide a pseudo-independent measure of ongoing student ability and engagement. As this evaluation was an internal Quality Assurance Activity, being designed around the University's Plan, Implement, Review, Improve (PIRI) Quality Improvement Framework, ethical approval from the University Human Research Ethics Committee was not required. All student data was de-identified and then analysed by a non-course or program associated third party (TB).

Data analysis:

Initially data from campus B (offering lecture capture) was analysed to determine patterns in success and of lecture capture usage using correlational analyses via SPSSx. The overall campus B results were then compared with the overall campus A results. Performance in both formative and summative assessment items at each campus and across each campus were analysed using multivariate analysis of variance (MANOVA) and SPSSx software. Qualitative data, including verbal and written feedback from students was grouped according to theme and presented to enhance and contextualise quantitative results 


\section{Results}

\section{Campus B}

Lectures live and recorded:

The initial result of lecture recording appeared to be one of overwhelming success with 10,979 hits recorded across the semester. Most (96\%) of enrolled students chose to access recorded lectures, with an average of 52.03 hits per student or 2 hits per student per lecture capture file. While qualitative evidence suggested that some of these hits were 'practice' hits (to check the file was loaded and they could view/hear it) the majority of these appeared to be actual viewing of the files. This concurred with student reports indicating that they found it a valuable resource. No formal record of attendance or head count was taken at the live lectures, however known lecture theatre capacity and occasional estimate checks indicated that on average approximately 110 students (around 53\% of the total enrolment) attended lectures, significantly fewer than expected based on previous years' attendance (usually at around $80-85 \%)$.

While the lecture capture data suggested that some students viewed the captured file instead of attending the live lecture, at an average total of 577 hits per week (c.f. total student enrolment of 211), it is clear that many students were accessing both live and recorded lectures and accessing recorded lectures multiple times. One of the themes that emerged very clearly from the survey data collected from the cohort across all of their first semester first year courses was that students felt that recorded lectures could not replace live face-to-face lectures, but rather supplemented the live big-class teaching (see Cooke, et al., 2012).

The distribution of timing of lecture hits supported student qualitative statements that recorded lectures enabled more flexible lecture access (see Fig. 1). Students clearly accessed the recorded lecture files as part of an engagement/revision process with peaks clearly shown 
around the weeks of summative assessment (mid semester exam, week 9 of semester and study week prior to end of semester exam, week 17; see Fig. 1A). There was no hour in the entire 24-hour distribution where students did not access lectures, although the 'day' (09.0016.00) and 'evening' (17.00-21.00) slots were by far the most commonly accessed times (Fig. 1B). Time of day analysis (Fig. 1B) indicated that the access times had a peak at 16:00 and a trough at 03:00.

Time of day access of lecture capture did not break down into days of the week - but curiously, the most popular times of access included $13.00 \& 16.00$, the same time as the face-to-face lectures (despite the delay between lecture delivery and lecture capture upload), indicating that it may not have been simply time of day which precluded students attendance at the lectures. Student comments supported this notion. "I like not having to listen to all the chat and just concentrate on the material" and "I like to be able to get a cup of tea and do it at my own pace". Others indicated that due to carer commitments (children, family commitments) and paid work they found the ability to review lectures in their own home and in their own time most valuable; "I don't have to find someone to look after the kids and get the bus to Uni. We all listen to the recordings and we often talk about them over dinner and when driving places". "I used to spend time at my kid's sports training and classes waiting, now I use that time to view the lectures and revise". It also appeared to fit in with other life activities "I walk/run nearly $20 \mathrm{~km}$ a week now - listening to the lectures".

While the bulk of qualitative data suggested that students generally did not consider recorded lectures as effective replacements for live lectures (see Cooke, et al., 2012), the pattern of lecture attendance ( $\sim 60 \%$ attendance) suggested otherwise. Student comments indicated that they considered the lectures optional to learning. "I didn't go to all the lectures 'cause I 
needed to do my assignments [for other courses] and I could always watch the recording". "I can't think at night [one lecture was held 4-6pm], too tired, but it was OK because I could listen to the lecture recordings whenever". Some students appeared to have sufficient insight to recognise that this perceived advantage may not be so beneficial after all. "I started listening to the lecture captures but then I missed one week - and there was so much stuff on I didn't really catch up". "I tried to listen to them all in study week, but it was just too much - blew my mind". "I tried listening to the lecture capture files - but without someone waving their hands about I got bored and easily distracted".

Lecture duration also clearly played a part in the number of hits onto a lecture. The two-hour live lecture slot was hit almost twice as often as the $1 \mathrm{hr}$ lecture slot - again indicating that perhaps students were using the lecture capture facility to go through material at their own pace. Hit rate was spread across all of the lectures, with the most popular lecture recorded being the introductory \& welcoming lecture outlining the format of the course (data not shown). Again, student comments supported these findings. "....my brain is dead after half an hour. I like to pause and then go back to it". "I can't keep concentrating for 2 hours, my mind wanders and then I realise I have missed something important. With lecture capture [recorded lectures] I can go back and 'get' that thing".

Academic performance:

Pearson correlation of hits on lecture capture compared to overall performance by students indicated a weak but significant relationship between these factors $(r=0.405, P<0.01,2$ tailed), suggesting that accessing recorded lectures was related to overall performance in the course. The most significantly related factors were hits on recorded lectures compared to performance in the final examination $(\mathrm{r}=0.452, \mathrm{P}<0.01,2$-tailed $)$. There were weaker 
correlations with performance in the mid-semester examination $(r=0.322)$, and performance in the laboratory assessments $(\mathrm{r}=0.282)$. While clearly there are many other factors with may also influence these outcomes, it ostensibly suggests that access to recorded lectures could improve student academic outcomes. Again, student feedback supported the idea that it was a valuable revision tool. “__ [lecturer] presents stuff so clearly, so when I get confused or I forget I go back to the lecture and listen again; it makes it clear". "I missed the lecture on because I had to complete my essay for [another course] so I listened to it on-line".

\section{Campus A versus Campus B}

Lectures live

Lecture attendance at campus A was high, at around $80-85 \%$ percent as per previous years. This high turn-out suggests that students recognise and appreciate the value of active engagement in learning and teaching presentations in courses they perceive as challenging. They do not have the option of replacing missing lectures with watching the recordings, and seem to find the more traditional alternative to lectures; working through the text and lecture notes individually, less desirable.

\section{Academic performance}

It was an apparent trend of poorer overall academic performance at Campus B, which initially prompted this investigation. Overall outright fail rates $(<50 \%$ overall performance having attempted all assessment items) were around $28 \%$ at Campus $\mathrm{A}$, compared to the $9 \%$ equivalent failure recorded the previous year and $13 \%$ the year before that. This change was not obviously associated with course factors, as an identical assessment strategy was used in all years and there was substantial assessment item overlap (reuse) during the two key years 
of investigation. Moreover, there were no significant modifications of curricular content, presentation or other factors we could identify as potentially influencing results (aside from student population). Further, student evaluation of the course and teaching staff remained overall high.

Overall performance at Campus A remained relatively unchanged, with outright fail rates being $18.6 \%$ compared to $18.2 \%$ in the previous year. Multivariate analysis of variance (MANOVA) indicated that students on Campus B performed marginally better in laboratorybased assessment than those on campus A (average percentage result \pm SEM, Campus B $58.25 \pm 1.09$ versus mean Campus A $54.3 \pm 0.96 ; \mathrm{F}_{1,463}=7.42, \mathrm{p}=0.009$ ). This comparison of formative laboratory-based assessment suggested that it was not simply the ability or engagement of the two cohorts that differed (see Fig. 2A). Moreover, performance in laboratory classes at Campus B did not vary based on accessing of recorded lecture files $(\mathrm{P}>0.05)$.

This small but significant difference in outcomes of laboratory assessment was reversed in both pieces of summative assessment (midsemester exam Campus B, $57.4 \pm 0.98$ versus mean Campus A $61.4 \pm 0.87 ; \mathrm{F}_{1,463}=9.4, \mathrm{p}=0.002$; end of semester exam Campus B, $51.3 \pm$ 1.13 versus mean Campus A $\left.63.1 \pm 0.99 ; \mathrm{F}_{1,463}=61, \mathrm{p}<0.001\right)$. This resulted in a highly significant difference in final scores on the two campuses (average cumulative score \pm SEM Campus B, $54.9 \pm 0.99$ versus Campus A $\left.60.2 \pm 0.87 ; \mathrm{F}_{1,463}=16.14, \mathrm{p}<0.001\right)$ demonstrating Campus A students performed consistently better in both summative assessment tasks (see Fig. 2B \& C) and thus in overall performance (see Fig. D). Students from Campus B who frequently accessed recorded lecture files marginally outperformed their 
colleagues (see Fig. 2), but still performed on average more poorly than their Campus A colleagues.

\section{Discussion}

This study confirmed findings of other such investigations showing that students respond positively to the ability to access lectures digitally, as a means of supplementing learning experiences (lectures, laboratory classes and self-directed learning) and, where required, replacing the lecture attendance . Data collected overwhelmingly supported the notion that students will, if given the opportunity, access recorded lectures frequently, across the entire day and across the entire semester - with obvious peaks immediately prior to assessment dates. It clearly enhanced the opportunity for flexible engagement with learning processes for time-poor students.

The distribution of accessing the recorded files may suggest that students accessed the files as a means of revising material prior to assessment dates, with significant peaks in the week prior to both examinations. However, qualitative feedback, coupled with recognition of poor lecture attendance at the campus where digitally recorded lectures were offered could also suggest that these immediate pre-exam periods may actually reflect the first engagement of some students with the lecture material content. Herein lies the first interesting discrepancy shown in this study. Consistent with previous studies (Koch et al 2010; Kelly et al 2009; McKinney and Page 2009; Freeman et al 2006; Salamonson and Lantz 2005), students overwhelmingly reported that digitally recorded lectures should be used to supplement, and not replace, traditional face-to-face lectures. However, they simultaneously apparently decreased or even ceased their attendance at live lectures, seemingly relying on heavy access to the recorded material immediately prior to major assessment tasks. This finding contrasts 
with other studies of student attendance at lectures that were also digitally recorded which concluded that students decisions about attending lectures are based on their goals to maximise learning and are not influenced by digital recordings (Billings-Gagliardi and Mazor, 2007). These studies, however, were conducted in medical students and perhaps raise some educational issues about different student populations and their varying needs. However, by not exploring the actual impact of student decisions on their academic performance such studies echo many others which appear to assume that students have the skills and background to be able to best judge which learning activities best engage and support their learning.

Few studies have compared academic outcome based on face-to-face or optional accessing (supplementation) of on-line materials by health students in tertiary learning environments. Where such studies have been conducted they have shown little if any effect of webenhancement on academic performance by students (Buckley, 2003; Hubble and Richards, 2006), though they have only explored data from a small number of students (less than 60 students per study). This contrasts with the results of the current study where there was a small, but significant, decrement in academic performance in the group given access to digitally recorded lectures (Campus B) compared to their colleagues at the other campus (A). It seemed that, unlike findings of other studies (Farrell et al., 2007; Hubble and Richards, 2006; McNulty, et al., 2000), access to this technology marginally reduced overall academic achievement (Mitchell et al., 2007; Solomon, et al., 2004). Comparison of laboratory-based written assessment indicated that this was unlikely to be related to lower academic ability in this group, because Campus B students performed marginally better than those from Campus A in the laboratory-based tests. 
Thus, examination of the data overall (pattern of access as well as number of accesses and relationship with overall performance) suggests that perhaps the ability to access digitally recorded lectures encourages 'cramming' in this student population, rather than ongoing engagement with course content. Rather than gradually building an interrelated working knowledge of anatomy and physiology across weeks of study, reinforced by laboratory activities; building and supporting deep and scaffolded learning, students are perhaps attempting to consolidate scant and disconnected laboratory-based exercises in a blocklearning paradigm. Unlike small modules presented in either an on-line or face-to-face manner where on-line learning has been shown to effectively enable students to consolidate and retain limited blocks of content (Bloomfield et al., 2010) it would seem that student engagement and learning a semester long, factually and content dense course (such as the anatomy and physiology unit in the current study) is not facilitated by this form of presentation. Moreover, it undermines the active process of engagement, interaction, reflection and reiteration required to learn such material (Mitchell, et al., 2007; Noble, et al., 2008; Toates, 2006).

There was an, albeit weak, relationship between online access of recorded lectures and overall academic performance at Campus B, mirroring other studies (Campbell et al., 2008) and contrasting with studies in which there was an inverse relationship between number of lectures viewed and exam scores (McNulty, et al., 2009). In a similar study of medical students a significant inverse correlation between academic performance and number of views of recorded lectures was reported (McNulty, et al., 2009). Overall accessing of lectures in this contrasting study was far lower than in the current study (many students did not view the majority of the lectures, " $60 \%$ of the students viewed less than $10 \%$ of the available videos") where $96 \%$ of enrolled students accessed the lecture files in the current 
study. However the number of hits per lecture was similar (mean 2.0-5.3 per student per lecture versus an average of 2 hits per lecture per student for all lectures in this study). Other studies of medical and allied health professionals conducted in similar academic areas, such as anatomy, have also highlighted that nursing students are more likely to repeatedly access lecture recordings (Noble, et al., 2008). Thus it would appear that, while digitally captured lectures could support effective revision by already engaged students, it can also disadvantage students who use it as a replacement for live lecture attendance.

\section{Study Limitations:}

There are a number of methodological limitations to this study which cannot be ignored. It was performed retrospectively, based on available data and thus there are a number of limitations to the study design and also potential confounds to study interpretation. However, given student-demand for recorded lectures it is unlikely that university policy will allow the deliberate withholding of recorded lectures from students, irrespective of the potential impact for less experienced learners or the strengths and potential weaknesses of the technology. Moreover, it is very difficult to control for the plethora of factors which contribute to academic outcomes by students. Despite these limitations, the findings of this study, based on results from more than 400 students, provided an alternate view of the benefits of digital lecture recording and the study team felt it was important to alert nurse educators to these possibilities. It can certainly inform academics who are considering the potential benefits and shortfalls of integrating, rather than simply replacing existing approaches with technological support in tertiary courses.

\section{Conclusions:}


The range of IT support for tertiary learning, including within nursing curricula is steadily increasing (Maag, 2004; Maag, 2005; Maag, 2006). Given student satisfaction with the integration of technologies such as digital recordings into tertiary learning and teaching environments locally and internationally (Cooke, et al., 2012; Kiteley and Ormrod, 2009; Lu et al., 2009) it seems unlikely that even the most negative reports of impact on academic performance will see them removed from university offerings. Mildly negative impacts of IT supports such as those reported in this study merely direct academic staff to consider supplementing IT course-enhancements like digital recordings with ongoing support to ensure that they are most effectively used by student populations. If IT and web-based course enhancements can ameliorate the powerful negative predictor of success, nonattendance (McCarey, et al., 2006; Salamonson and Andrew, 2006), then they clearly have a part to play in the development of new curricula and academic learning and teaching strategies. Academics may have to think more creatively, however, about how to integrate digital recordings into a program of study that effectively provides ongoing support to nursing students (Salamonson and Lantz, 2005) in which students remain engaged and feel supported (Shelton, 2003). Student support will necessarily include developing IT skills in this population (Creedy et al., 2007; Sitzmann et al., 2010; Wilkinson et al., 2009) and also guidelines for the best use of digitally recorded lecture material. Digitally recorded lectures can clearly help support students struggling with medical terminology (usage and even pronunciation), revising difficult concepts, reviewing material prior to laboratory exercises or examinations and also support students who might otherwise not have the opportunity to listen to an enhanced and developed presentation of material. However there is a way to go before academics can develop strategies to ensure the most effective use of such technologies to best support student learning and engagement in all courses, but particularly those which require consistent effort on the part of students to keep abreast of complex curricular content. 
Hit rate distribution across weeks of semester

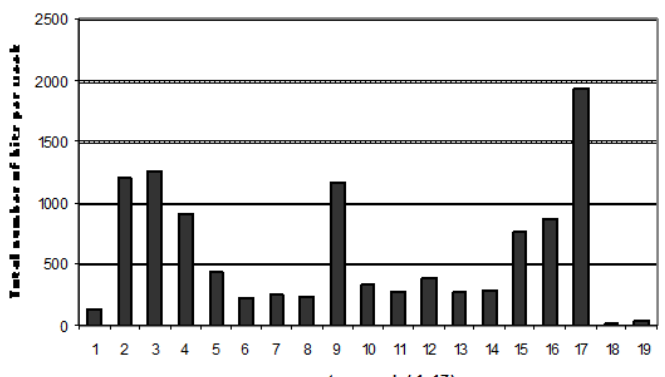

A.

Figure 1. Distribution of 'hits' onto digitally-recorded lectures by students across the semester. A. shows the hits divided by weeks of the semester, with distinctive peaks around exam assessment weeks ( $9 \& 17)$. B. shows the total number of hits across the semester grouped by time of day matched to a polynomial line of best fit.

(Kelly, Lyng, McGrath, \& Cannon, 2009)

(McKinney \& Page, 2009)

(Freeman, Schrimsher, \& Kendrach, 2006) 


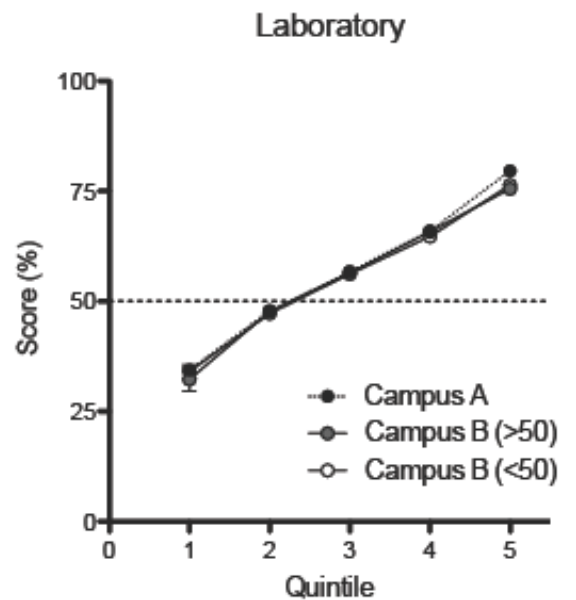

Mid Semester

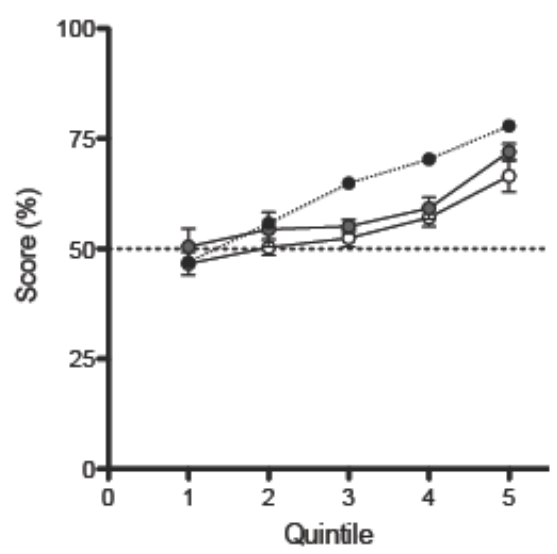

End Semester

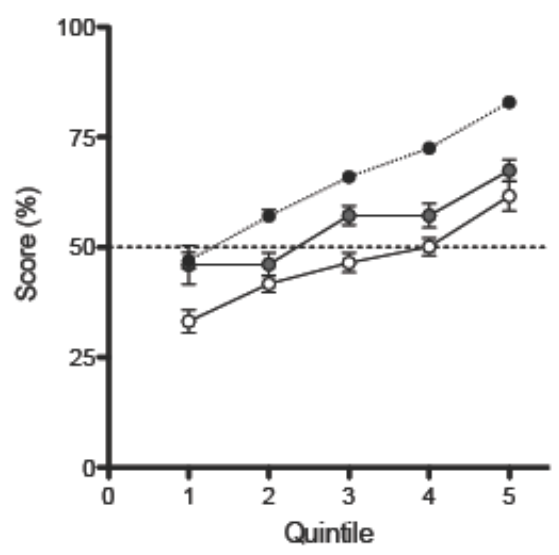

Final Score

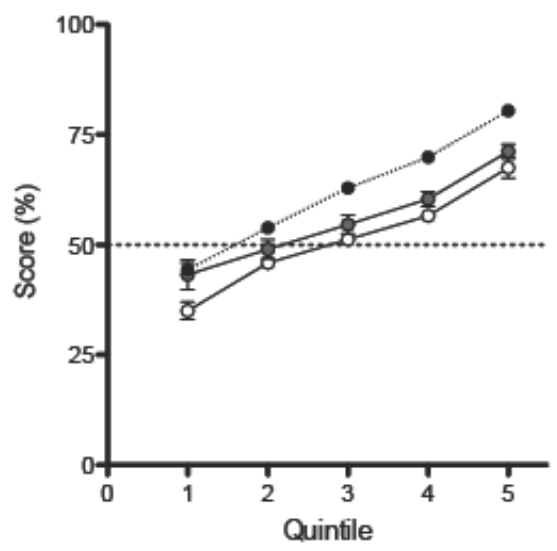

Figure 2. Academic outcomes, assessed by percentage scores in formative assessment (laboratory-based, A), summative assessment (midsemester examination, B \& end of semester examination, C) and cumulative (summed) assessment (D) varied across campus A \& B, divided into score quintiles for each measure. Student results were divided, by success, into quintiles to enable detailed performance to be viewed diagrammatically. While both cohorts performed equally well in laboratory based assessment, irrespective of access to lecture capture (A), performance on summative assessments was lower in the cohort with access to recorded lectures (campus B), irrespective of whether they accessed recorded lectures frequently ( $>50$ hits) or infrequently ( $<50$ hits).

\section{Acknowledgements}

The authors acknowledge Paul Brown for his support enabling presentation of digitally recorded lectures and for his input in enabling accessing of student usage of the recordings. 


\section{References}

AustralianVice-Chancellors'Committee. Undergraduate student finances in 2006 Fact sheet 2007.

Billings-Gagliardi, S., Mazor, K. M. 2007. Student decisions about lecture attendance: do electronic course materials matter? Academic Medicine 82 (10 Suppl), S73-76.

Billings, D. M., Skiba, D. J., Connors, H. R. 2005. Best practices in Web-based courses: generational differences across undergraduate and graduate nursing students. Journal of Professional Nursing 21 (2), 126-133.

Bloomfield, J., Roberts, J., While, A. 2010. The effect of computer-assisted learning versus conventional teaching methods on the acquisition and retention of handwashing theory and skills in pre-qualification nursing students: a randomised controlled trial. International Journal of Nursing Studies 47 (3), 287-294.

Buckley, K. M. 2003. Evaluation of classroom-based, Web-enhanced, and Web-based distance learning nutrition courses for undergraduate nursing. Journal of Nursing Education 42 (8), 367-370.

Campbell, M., Gibson, W., Hall, A., Richards, D., Callery, P. 2008. Online vs. face-to-face discussion in a Web-based research methods course for postgraduate nursing students: a quasi-experimental study. International Journal of Nursing Studies 45 (5), 750-759.

Cardall, S., Krupat, E., Ulrich, M. 2008. Live lecture versus video-recorded lecture: are students voting with their feet? Academic Medicine 83 (12), 1174-1178.

Clancy, J., McVicar, A., Bird, D. 2000. Getting it right? An exploration of issues relating to the biological sciences in nurse education and nursing practice. Journal of Advanced Nursing 32 (6), 1522-1532.

Cooke, M., Watson, B., Blacklock, E., Mansah, M., Howard, M., Johnston, A. N. B., Tower, M., Murfield, J. 2012. Lecture Capture: first year student nurses' experiences of a web-based lecture technology. Australian Journal of Advanced Nursing 29(3), 14-21.

Courtenay, M. 1991. A study of the teaching and learning of the biological sciences in nurse education. Journal of Advanced Nursing 16 (9), 1110-1116.

Creedy, D. K., Mitchell, M., Seaton-Sykes, P., Cooke, M., Patterson, E., Purcell, C., Weeks, P. 2007. Evaluating a Web-enhanced bachelor of nursing curriculum: perspectives of third-year students. Journal of Nursing Education 46 (10), 460-467.

Davies, S., Murphy, F., Jordan, S. 2000. Bioscience in the pre-registration curriculum: finding the right teaching strategy. Nurse Education Today 20 (2), 123-135.

Farrell, G. A., Cubit, K. A., Bobrowski, C. L., Salmon, P. 2007. Using the WWW to teach undergraduate nurses clinical communication. Nurse Education Today 27 (5), 427 435. 
Goldberg, H. R., McKhann, G. M. 2000. Student test scores are improved in a virtual learning environment. Advances in Physiological Education 23 (1), 59-66.

Goldberg, H. R., Dintzis, R. 2007. The positive impact of team-based virtual microscopy on student learning in physiology and histology. Advances in Physiological Education 31 (3), 261-265.

Gosper, M., McNeill, M., Woo, K., Phillips, R., Preston, G., Green, D. Web-based lecture recording technologies: Do students learn from them? http://www.cpd.mq.edu.au/teaching/wblt/overview.htm; 2006.

Green, S., Voegeli, D., Harrison, M., Phillips, J., Knowles, J., Weaver, M., Shephard, M. 2003. Evaluating the use of streaming video to support student learning in a first-year life sciences course for student nurses Nurse Education Today 23 (4), 255-261.

Green, S. M., Weaver, M., Voegeli, D., Fitzsimmons, D., Knowles, J., Harrison, M., Shephard, K. 2006. The development and evaluation of the use of a virtual learning environment (Blackboard 5) to support the learning of pre-qualifying nursing students undertaking a human anatomy and physiology module. Nurse Education Today 26 (5), 388-395.

Gresty, K. A., Cotton, D. R. 2003. Supporting biosciences in the nursing curriculum: development and evaluation of an online resource. Journal of Advanced Nursing 44 (4), 339-349.

Hodson, D. 1998. Teaching and learning science Towards a personalized approach. Buckingham: Open University Press: Pages 256.

Holliman, R., Scanlon, E. 2004. Mediating science learning through information and communications technology (ICT). London: RoutledgeFalmer: Pages 301.

Hubble, M. W., Richards, M. E. 2006. Paramedic student performance: comparison of online with on-campus lecture delivery methods. Prehospital Disaster Medicine 21 (4), 261267.

Jang, K. S., Hwang, S. Y., Park, S. J., Kim, Y. M., Kim, M. J. 2005. Effects of a Web-based teaching method on undergraduate nursing students' learning of electrocardiography. Journal of Nursing Education 44 (1), 35-39.

Johnston, A. N. 2009. Anatomy for nurses: providing students with the best learning experience. Nurse Education in Practice 10 (4), 222-226.

Johnston, A. N. B., McAllister, M. 2008. Back to the future with hands-on science. Journal of Nursing Education 7 (9), 417-421.

Jones, S. E. 2010. Reflections on the lecture: outmoded medium or instrument of inspiration? Journal of Further and Higher Education 31 (4), 397-406.

Kevern, J., Webb, C. 2004. Mature women's experiences of preregistration nurse education. Journal of Advanced Nursing 45 (3), 297-306. 
Kiteley, R. J., Ormrod, G. 2009. Towards a team-based, collaborative approach to embedding e-learning within undergraduate nursing programmes. Nurse Education Today 29 (6), 623-629.

Koch, J., Andrew, S., Salamonson, Y., Everett, B., Davidson, P. M. 2010. Nursing students' perception of a web-based intervention to support learning. Nurse Education Today 30 (6), 584-590.

Kornguth, M., Frisch, N., Shovein, J., Williams, R. 1994. Noncognitive factors that put students at academic risk in nursing programs. Nurse Educator 19 (5), 24-27.

Lewis, D. J., Sewell, R. D. 2007. Providing formative feedback from a summative computeraided assessment. American Journal of Pharmacological Education 71 (2), 33.

Lu, D. F., Lin, Z. C., Li, Y. J. 2009. Effects of a Web-based course on nursing skills and knowledge learning. Journal of Nurse Education 48 (2), 70-77.

Maag, M. 2004. The effectiveness of an interactive multimedia learning tool on nursing students' math knowledge and self-efficacy. Computing Informatics and Nursing 22 (1), 26-33.

Maag, M. 2005. The potential use of "blogs" in nursing education. Computing Informatics and Nursing 23 (1), 16-24; quiz 25-16.

Maag, M. 2006. Podcasting and MP3 players: emerging education technologies. Computing Informatics and Nursing 24 (1), 9-13.

Maag, M. 2006. Podcasting: An emerging technology in nursing education. Student Health Technology Informatics 122 835-836.

Maag, M. M. 2006. Nursing students' attitudes toward technology: a national study. Nurse Educator 31 (3), 112-118.

Massingham, P., Herrington, T. 2009. Does Attendance Matter? An Examination of Student Attitudes, Participation, Performance and Attendance. Journal of University Teaching and Learning Practice 3 82-103.

McCarey, M., Barr, T., Rattray, J. 2006. Predictors of academic performance in a cohort of pre-registration nursing students. Nurse Education Today 27 (4), 357-364.

McNeill, M., Woo, K., Gosper, M., Preston, G., Green, D. Web-based lecture recording technologies - advice from students. HERDSA. Adelaide: http://www.cpd.mq.edu.au/teaching/wblt/dissemination.htm/HERDSA_McNeill.pdf; 2007.

McNulty, J. A., Halama, J., Dauzvardis, M. F., Espiritu, B. 2000. Evaluation of Web-based computer-aided instruction in a basic science course. Academic Medicine 75 (1), 5965 . 
McNulty, J. A., Hoyt, A., Gruener, G., Chandrasekhar, A., Espiritu, B., Price, R., Jr., Naheedy, R. 2009. An analysis of lecture video utilization in undergraduate medical education: associations with performance in the courses. BMC Medical Education 9, 6.

Mitchell, E. A., Ryan, A., Carson, O., McCann, S. 2007. An exploratory study of webenhanced learning in undergraduate nurse education. Journal of Clinical Nursing 16 (12), 2287-2296.

Noble, K. A., Miller, S. M., Heckman, J. 2008. The cognitive style of nursing students: educational implications for teaching and learning. Journal of Nurse Education 47 (6), 245-253.

Phillips, R., Gosper, M., McNeill, M., Woo, K., Preston, G., Green, D. Web-based lecture recording technologies: Do students learn from them? Australasian Society for Computers In Learning In Tertiary Education (ASCILITE). Singapore: http://www.cpd.mq.edu.au/teaching/wblt/dissemination.htm/HERDSA_McNeill.pdf; 2007.

Ramsden, P., Prosser, M., Trigwell, K., Martin, E. 2007. University teachers' experiences of academic leadership and their approaches to teaching. Learning and Instruction, 17, $140-155$.

Rochford, C., Connolly, M., Drennan, J. 2009. Paid part-time employment and academic performance of undergraduate nursing students. Nurse Education Today 29 (6), 601606.

Rouse, D. P. 2000. The effectiveness of computer-assisted instruction in teaching nursing students about congenital heart disease. Computers in Nursing 18, 282-287.

Salamonson, Y., Lantz, J. 2005. Factors influencing nursing students' preference for a hybrid format delivery in a pathophysiology course. Nurse Education Today 25 (1), 9-16.

Salamonson, Y., Andrew, S. 2006. Academic performance in nursing students: influence of part-time employment, age and ethnicity. Journal of Advanced Nursing 55 (3), 342349; discussion 350-341.

Salyers, V. L. 2005. Web-enhanced and face-to-face classroom instructional methods: effects on course outcomes and student satisfaction. International Journal of Nursing Education Scholarship 2 Article 29.

Scanlon, E., Murphy, P., Thomas, J., Whitelegg, E., eds. 2004. Reconsidering science learning. London: RoutledgeFalmer: Pages 223.

Shelton, E. N. 2003. Faculty support and student retention. Journal of Nursing Education 42 (2), 68-76.

Sitzmann, T., Ely, K., Bell, B. S., Bauer, K. N. 2010. The effects of technical difficulties on learning and attrition during online training. Journal of Experimental Psychology Applied 16 (3), 281-292. 
Solomon, D. J., Ferenchick, G. S., Laird-Fick, H. S., Kavanaugh, K. 2004. A randomized trial comparing digital and live lecture formats [ISRCTN40455708. BMC Medical Education 4, 27.

Soong, S. K. A., Chan, L. K., Cheers, C., Hu, C. Impact of video recorded lectures among students. Australasian Society for Computers In Learning In Tertiary Education (ASCILITE). Sydney:

http://www.ascilite.org.au/conferences/sydney06/proceedings/pdf_papers/p179.pdf; 2006.

Spitzer, A., Perrenoud, B. 2006. Reforms in nursing education across Western Europe: implementation processes and current status. Journal of Professional Nursing 22 (3), $162-171$.

Tanner, C. A. 2001. Measurement and evaluation in nursing education. Journal of Nursing Education 40 (1), 3-4.

Toates, F. 2006. Biological Psychology. London: Prentice-Hall: Pages 627.

Weatherall, D. J. 2006. Science in the undergraduate curriculum during the 20th century. Medical Education 40 (3), 195-201.

Wharrad, H. J., Cook, E., Poussa, C. 2005. Putting post-registration nursing students on-line: important lessons learned. Nurse Education Today 25 (4), 263-271.

Wilkinson, A., While, A. E., Roberts, J. 2009. Measurement of information and communication technology experience and attitudes to e-learning of students in the healthcare professions: integrative review. Journal of Advanced Nursing 65 (4), 755 772.

Freeman, M. K., Schrimsher, R. H., \& Kendrach, M. G. (2006). Student perceptions of online lectures and WebCT in an introductory drug information course. [Comparative Study]. Am J Pharm Educ, 70(6), 126.

Kelly, M., Lyng, C., McGrath, M., \& Cannon, G. (2009). A multi-method study to determine the effectiveness of, and student attitudes to, online instructional videos for teaching clinical nursing skills. Nurse Education Today, 29(3), 292-300.

McKinney, A. A., \& Page, K. (2009). Podcasts and videostreaming: Useful tools to facilitate learning of pathophysiology in undergraduate nurse education? Nurse Education in Practice, 9(6), 372-376. 